\title{
Obstáculos didáticos no cotidiano da prática pedagógica do enfermeiro professor
}

\author{
Educational obstacles in the everyday living of the nurse teacher's pedagogical practice \\ Obstáculos didácticos en el cotidiano de la práctica pedagógica del enfermero profesor
}

\author{
Malvina Thaís Pacheco Rodrigues', José Augusto de Carvalho Mendes Sobrinho"I \\ 'Colégio Agrícola de Teresina. Teresina, PI \\ "Universidade Federal do Piauí. Teresina, PI
}

Submissão: 19/03/2008

Aprovação: 31/07/2008

\section{RESUMO}

A docência universitária emerge como uma temática freeüentemente discutida no cenário educacional. Este artigo tem como objetivo investigar os obstáculos didáticos emergentes no cotidiano da prática pedagógica do enfermeiro professor do Curso de Graduação em Enfermagem da UESPI, com o intuito de subsidiar a elaboração de propostas de superação desses obstáculos. Trata-se de um estudo descritivo-interpretativo de abordagem Qualitativa tendo como instrumentos de coleta de dados Questionário e entrevista semi-estruturada e a análise dos dados a partir da análise de conteúdo. Pelas análises, evidencia-se que os obstáculos didáticos estão relacionados à pessoa do professor, aos alunos e à instituição. Assim, é proposto a implantação de um programa de formação continuada na perspectiva da ação-reflexão-ação como forma de superação dos obstáculos.

Descritores: Ensino; Programas de graduação em enfermagem; Educação em enfermagem.

\section{ABSTRACT}

University teaching emerges as a theme frequently discussed in the educational scene. This article aims to investigate the educational obstacles emerging in the everyday living of the pedagogical practice of the nurse teacher from the Nursing Graduation Course at UEPSI, wishing to subsidize the elaboration of proposals for overcoming of these obstacles. It is a study of Qualitative approach with data collection, Questionnaire and semi-structured interview and data analysis through content analysis. According to the analysis, it is clear that the educational obstacles relate to the teacher person, to the students and to the institution. Thus, an establishment of a continuing education program in the action-reflection-action perspective is proposed as a way of overcoming the obstacles.

Descriptors: Teaching; Education, nursing, diploma programs; Education, nursing.

\section{RESUMEN}

La docencia universitaria surge como una temática frecuentemente discutida en el escenario educacional. Este artículo objetiva investigar los obstáculos didácticos en el cotidiano de la práctica pedagógica del enfermero profesor del Curso de Graduación en Enfermería de UESPI, deseando subsidiar la elaboración de propuestas de superación de estos obstáculos. Es un estudio descriptivo-interpretativo de abordaje cualitativo, con colecta de datos, cuestionario y entrevista semiestructurada y el análisis de datos por medio del análisis de contenido. En acuerdo con los análisis, tornase claro Que los obstáculos didácticos están relacionados con el profesor, con los alumnos y con la institución. Por lo tanto, es propuesto el establecimiento de un programa de formación continuada en la perspectiva de acciónreacción-acción como forma de superación de los obstáculos.

Descriptores: Enseñanza; Programas de graduación en enfermería; Educación en enfermería. 


\section{INTRODUÇÃO}

A formação, o desempenho e o desenvolvimento profissional do professor têm sido objeto de análise e estudos a partir do movimento de transformação do ensino superior no Brasil. Atualmente, espera-se do docente universitário que ele forme profissionais competentes e comprometidos socialmente, tendo a prática educativa a função de desenvolvimento pessoal e social com preocupações formativas, além de informativas. Nesse sentido, é necessária a busca de uma prática docente Que possibilite aos alunos um pensamento crítico, a partir da valorização da criatividade, da reflexão e da participação, condições indispensáveis para a inserção social e construção da cidadania.

Assim, o papel do professor universitário deve ser repensado a partir de três competências para a docência no ensino superior: ser competente em uma determinada área de conhecimento, ter domínio na área pedagógica e exercer a dimensão política. A primeira delas se refere ao domínio dos conhecimentos básicos da área e à experiência profissional do campo enQuanto a segunda envolve o domínio do conceito do processo de ensinoaprendizagem, integrando o desenvolvimento cognitivo, o afetivoemocional e as habilidades, bem como a formação de atitudes, abrindo espaços para a interação e a interdisciplinaridade. lá a terceira competência abrange a discussão dos aspectos políticos e éticos da profissão e do seu exercício na sociedade, de forma Que os docentes possam se posicionar como cidadãos, políticos e profissionais comprometidos com a comunidade. Assim, um professor do ensino superior deve aliar o conhecimento específico da área ao domínio da habilidade de educar ${ }^{(1)}$.

Nessa perspectiva, um fator primordial para Que o enfermeiro professor seja competente no exercício da docência universitária é Que ele identifieue e supere os obstáculos didáticos, entendendose estes como tudo que interfere negativamente no processo ensinoaprendizagem, não estando eles limitados ao espaço físico da sala de aula. Preocupa-nos, nesse sentido, a discussão não somente da prática pedagógica Que temos, mas da prática pedagógica Que Queremos, objetivando encontrar possibilidades concretas de superar tais obstáculos. Sendo assim, idealizamos uma pesquisa Que busca identificar os obstáculos didáticos Que os enfermeiros professores enfrentam no exercício cotidiano da docência superior, bem como as suas formas de superação.

Essa análise acerca dos obstáculos está referenciada em Bachelard $^{(2)}$, e a Questão central à Qual procuramos responder ao longo da pesQuisa foi: Quais são os obstáculos didáticos inerentes à prática pedagógica do enfermeiro professor do Curso de Graduação em Enfermagem da Universidade Estadual do Piauí (UESPI) e Quais as formas de superá-los?

\section{METODOLOGIA}

Este estudo é uma pesquisa Que emprega o método Qualitativo, visto Que nossa intenção foi ir ao encontro das experiências e vivências cotidianas da prática docente dos enfermeiros, a partir dos seus discursos.

A pesquisa foi desenvolvida no município de Teresina (PI), no curso de Graduação em Enfermagem da Faculdade de Ciências Médicas (FACIME) da UESPI. Escolhemos essa IES porque se trata de uma universidade pública Que oferece Graduação em Enfermagem em várias cidades do estado, possibilitando a interiorização do ensino superior e a formação de alunos em todo o estado do Piaú, e ainda pelo fato da nossa experiência na docência de nível superior ter sido iniciada nessa universidade.

Os sujeitos investigados foram todos os professores efetivos do Curso de Graduação em Enfermagem da UESPI, por entendermos Que o vínculo duradouro com a instituição possibilita a contribuição de forma mais relevante para a pesQuisa. A participação dos docentes foi voluntária e obtivemos o consentimento livre e esclarecido de cada um, obedecendo à Resolução de no. 196/96, do Ministério da Saúde, Que regula as pesquisas nacionais com seres humanos ${ }^{(3)}$.

Para garantir o anonimato dos sujeitos, utilizamos códigos compostos por duas letras - EP (Enfermeiro Professor) - e dois números (01 a 14) - EPOI a EPI4. A codificação ocorreu de acordo com a realização das entrevistas. Dessa forma, EP0I foi o primeiro enfermeiro professor entrevistado.

Após a aprovação da pesquisa pelo Comitê de Ética da FACIME, iniciamos a coleta de dados, realizada em agosto de 2007 , utilizando um Questionário denominado instrumento de caracterização dos sujeitos e uma entrevista semi-estruturada, na perspectiva da narrativa.

As entrevistas seguiram um roteiro em Que foram Questionados os seguintes aspectos: ingresso na docência superior, formação pedagógica, prática pedagógica, referenciais pedagógicos e obstáculos encontrados no exercício da docência. A utilização de Questionários permitiu obter dados de caracterização dos sujeitos e, assim, traçou-se o perfil da amostra.

Para análise dos dados utilizamos a técnica de análise de conteúdo ${ }^{(4)}$, sendo Que a árvore categorial se compôs da seguinte forma: Categoria 1: Prática pedagógica, com as subcategorias: a) Ingresso na docência, b) Formação pedagógica, c) Características da prática pedagógica; Categoria 2: Obstáculos didáticos, e as subcategorias: a) Obstáculos didáticos e o professor, b) Obstáculos didáticos e o aluno, c) Obstáculos didáticos e a instituição; Categoria 3: O enfermeiro professor e o diálogo com os obstáculos, e as subcategorias: a) Superação dos obstáculos didáticos na perspectiva dos enfermeiros professores da UESPI, b) Proposta de superação dos obstáculos didáticos na perspectiva da pesquisadora.

\section{RESULTADOS E DISCUSSÃO}

\section{Categoria 1: Prática pedagógica do enfermeiro professor}

Os enfermeiros professores demonstraram, de forma muito clara, a complexidade do trabalho docente, evidenciando a necessidade de comprometimento com as Questões pedagógicas a fim de Que ocorra uma transformação no ensino de Enfermagem. Mostraram Que têm consciência da necessidade da formação pedagógica bem como de Que suas práticas docentes precisam de mudanças. Para isso, estão dispostos a redirecionar conceitos e superar um ensino focado na reprodução do conhecimento, a partir da adoção de uma prática pedagógica Que supere o paradigma do tradicionalismo e do tecnicismo e Que seja pautada na construção do conhecimento e no contexto social. Segundo os entrevistados, evidentemente, é preciso estar envolvidos nesse processo de superação todos os responsáveis diretos por tal mudança: professores, alunos e 
instituição.

As narrativas dos enfermeiros professores acerca de sua prática pedagógica levaram-nos a dividir essa categoria em três subcategorias (ingresso na docência, formação pedagógica e características da prática pedagógica), detalhadas a seguir.

\section{Ingresso na docência}

Nessa subcategoria, os enfermeiros professores do Curso de Enfermagem da UESPI relatam como ocorreu o ingresso na docência superior. Pudemos constatar Que isso se deu como decorrência natural de suas atividades profissionais e ainda por motivos diversos (forma de complementar salário, novas oportunidades de trabalho, continuar estudando etc.). Tais justificativas corroboram outra pesquisa, realizada com os professores bacharéis do ensino superior $^{(5)}$.

Outros enfermeiros professores tiveram contato com a profissão docente através de cursos na área da Educação (Educação Artística, Normal, Pedagógico e Matemática) antes de se tornarem enfermeiros, o Que influenciou marcantemente a escolha pela profissão professor. EPI2 e EP09 demonstraram interesse em ser professor desde a graduação. EP08 afirma Que o principal motivo do seu ingresso na docência foi a vontade de mudar a forma como era conduzido o processo de ensinar e aprender. Também observamos, em duas falas, a influência do contexto familiar, onde se deu a vivência com profissionais da área, sendo a família a grande motivadora para a escolha da docência.

\section{Formação pedagógica}

Tornar-se professor reQuer competências Que não são inatas e, portanto, precisam ser construídas. Essa construção deve estar fundamentada na reflexão crítica sobre a prática profissional bem como sobre o contexto histórico, social, político e cultural em Que essa prática se processa. Tradicionalmente, o saber pedagógico não é pré-requisito para o ingresso na docência superior, e, em conseeüência disso, os professores bacharéis, na grande maioria, exercem as atividades próprias da docência mesmo sem ter nenhuma preparação para essa nova função. Assim, a idéia de Que "Quem sabe fazer sabe ensinar" predomina na contratação dos professores de nível superior ${ }^{(6)}$.

A capacitação dos profissionais liberais para o exercício do magistério do terceiro grau é uma necessidade urgente e real, e não se trata de uma tarefa fácil, devido à ausência da tradição de cursos destinados à preparação desses professores; do temor da perda de status e da acomodação ou não reconhecimento da importância da formação pedagógica ${ }^{(7)}$. Reportando-nos para o ensino em saúde, em geral, a complexidade Que envolve a docência é considerada secundária, deixando-se de reconhecer a triangulação entre ensino, aprendizagem e assistência ${ }^{(8)}$.

Nesta pesquisa, os interlocutores foram unânimes em afirmar Que os enfermeiros Que Querem tornar-se professores ou já são professores precisam adQuirir formação específica para a docência, elemento importante e necessário para o desempenho dessa função. Pelas narrativas, os enfermeiros professores demonstram ter consciência de que o bacharelado os torna enfermeiros, e não professores, e Que adentrar no campo da docência exige formação específica.

A busca da formação pedagógica dos enfermeiros professores da UESPI geralmente acontece em cursos de pós-graduação lato sensu e stricto sensu na área da saúde e em pós-graduação lato sensu específica para a docência.

Neste estudo, constatamos Que oito professores fizeram pósgraduação específica para a docência, sendo importante salientar Que, em relação a essa formação, cinco enfermeiros participaram de um curso direcionado para o ensino no nível médio de Enfermagem, desenvolvido a distância pela Escola Nacional de Saúde Pública da Fundação Oswaldo Cruz - FIOCRUZ, em articulação com a Secretaria de Gestão de Investimento em saúde - SIS, do Ministério da Saúde, dentro do processo de formação de auxiliares de enfermagem promovido pelo Projeto de Profissionalização dos Trabalhadores da área de Enfermagem PROFAE ocorrido em todo o Brasil. Dessa forma, não se trata de uma preparação para a docência superior, na Qual estão inseridos atualmente. Entretanto, essa foi a única oportunidade para os docentes, em nível de pós-graduação, de articular o ser enfermeiro e o ser professor através de conhecimentos de diferentes áreas Que embasam os conhecimentos da área da Enfermagem e da Educação, de forma a adQuirir competências básicas para o exercício da docência, mesmo numa formação direcionada para o nível médio. Todos destacaram a enorme contribuição dessa especialização no processo de construção do tornar-se professor.

\section{Características da Prática Pedagógica}

Nessa subcategoria, os enfermeiros professores da UESPI caracterizam sua prática pedagógica, sendo Que a maioria não a relaciona a uma única teoria pedagógica.

A prática descrita por eles é composta de uma mistura de paradigmas Que envolvem a produção do conhecimento, o trabalho conjunto de enfermeiros professores e alunos, o aprender a aprender, bem como apresenta características de uma prática tradicional. Nesse aspecto, os interlocutores entendem Que o ensino pautado somente na abordagem tradicional não mais atende às necessidades atuais, devendo os professores permitir Que os alunos desenvolvam suas capacidades de Questionamento, discussão, análise e construção do conhecimento.

Pelas falas percebe-se a tentativa de ruptura com os paradigmas tradicionais, em que o professor era detentor do conhecimento, sendo o aluno uma "tabula rasa". Nesse sentido, observamos Que os enfermeiros professores estão conscientes de Que a mudança é uma tarefa árdua e Que exige muita dedicação e esforço, já Que é muito difícil fazer com Que o tecnicismo deixe de ser, de imediato, o modelo básico da ação docente, visto Que a racionalidade técnica está fortemente presente na formação do enfermeiro. Assim, sabendo-se Que transformações não ocorrem de uma hora para outra, torna-se essencial Que façam parte da vivência cotidiana dos professores.

\section{Categoria 2: Obstáculos didáticos}

Nessa categoria, trabalhamos especificamente com o problema central da nossa pesQuisa: obstáculos didáticos, cuja análise está referenciada em Bachelard ${ }^{(2)}$. Pelas narrativas, agrupamos os obstáculos em três subcategorias, Que constituem as condições causais dos obstáculos, assim denominadas: obstáculos didáticos e o professor, obstáculos didáticos e o aluno e obstáculos didáticos e a instituição. 


\section{Obstáculos didáticos e o professor}

Nessa subcategoria, descrevemos os obstáculos didáticos relacionados ao professor, constatando-se os seguintes: lacuna na preparação específica para o exercício da docência, prática pedagógica sustentada pela dicotomia teoria-prática, trabalho didático com disciplinas das Quais não têm domínio de conteúdo, linguagem e dificuldade de mudança da prática pedagógica. $\mathrm{O}$ obstáculo decorrente da lacuna na preparação pedagógica foi o mais citado pelos enfermeiros professores.

As narrativas trazem manifestações Que evidenciam as dificuldades de ser professor e de adentrar um campo para a Qual não se está preparado. Constatamos Que os professores universitários não dominam a área educacional e pedagógica nem do ponto de vista filosófico nem do ponto de vista tecnológico, mas demonstram Que estão se dando conta da importância dessa formação pedagógica, buscando cursos de aperfeiçoamento e pósgraduação nessa área ${ }^{(9)}$.

Lançando um olhar para o ensino de enfermagem, em estudo realizado com enfermeiras professoras da Universidade Federal do Piauí ${ }^{(10)}$, constatou-se Que a prática docente ainda é marcada pelo domínio técnico e pela falta de domínio pedagógico, repetindo-se a realidade vivenciada pelos enfermeiros professores da UESPI.

\section{Obstáculos Didáticos e o Aluno}

Os atores centrais do processo ensino-aprendizagem são os professores e alunos, portanto é essencial Que estes sejam considerados na ação docente, levando-se em conta suas influências no processo de aprender. Dentre os obstáculos relacionados aos alunos, os enfermeiros professores da UESPI destacaram a deficiência na base teórica, o ingresso na universidade cada vez mais cedo, ou seja, a imaturidade, e a falta de preparo para lidar com a mudança da prática pedagógica do professor.

Com a ampliação da oferta de cursos superiores de Enfermagem, os alunos estão entrando cada dia mais precocemente no terceiro grau. Como conseqüência, sua base teórica é deficiente, e a idade é incompatível com essa nova etapa da vida acadêmica. Esse fato, conforme expressado pelos enfermeiros professores, interfere de forma negativa na condução do processo ensino-aprendizagem, e, dessa forma, os docentes convivem com obstáculos Que se apresentam sob a forma de desinteresse e indisciplina, juntamente com a deficiência de base teórica.

\section{Obstáculos Didáticos e a Instituição}

Em relação à instituição, foi constatado Que as condições deficientes de recursos, estrutura, campo de estágio e baixos salários estabelecem limites para o bom desempenho do trabalho do professor, constituindo-se também como obstáculos didáticos.

Essa situação acarreta para o docente estresse e falta de tempo para se dedicar à profissão, cujos salários são aviltantemente baixos, o que faz com que os professores ampliem sua jornada de trabalho, submetendo-se até mesmo a trabalhar os três turnos a fim de conseguir condições econômicas para sobreviver ${ }^{(11)}$.

Também foi evidenciado o descontentamento dos professores devido a UESPI não oferecer formação continuada, considerada essencial Quando se pensa no ensino superior de Qualidade. Nesse sentido, a formação do enfermeiro professor deve ser baseada em conhecimentos sistematizados Que contemplem aspectos específicos da área, pedagógicos e político-sociais, os Quais, indiscutivelmente, devem ser oferecidos pelas instituições nas Quais os professores trabalham. Somente dessa forma o enfermeiro professor pode redimensionar sua prática pedagógica.

\section{Categoria 3: O professor e o Diálogo com os Obstáculos Superação dos Obstáculos Didáticos na Perspectiva dos Enfermeiros Professores da UESPI}

Nossos interlocutores apontam Que estudar constitui a principal forma de superação dos obstáculos encontrados no ofício docente, ressaltando-se também a reflexão sobre a prática docente e a experiência. Para isso, afirmam Que a auto-avaliação é um importante recurso para se compreender o sentido da prática pedagógica no ensino superior, servindo para auxiliar nas reflexões Que o professor desenvolve em relação à condução do processo ensinoaprendizagem e ao seu comprometimento como sujeito ativador de mudanças, além de possibilitar alterações e o conseqüente aperfeiçoamento de sua prática docente. Outros professores utilizam a avaliação da disciplina no final do período como instrumento de reflexão sobre a prática, objetivando a superação dos obstáculos.

\section{Contribuições da Formação Inicial e da Formação Continuada}

Nessa subcategoria, procuramos relacionar a importância da formação inicial e da continuada como instrumentos de superação dos obstáculos da prática pedagógica. Em relação à formação inicial, a maioria dos enfermeiros professores relata Que teve pouca contribuição na superação dos obstáculos didáticos visto Que, como descrito anteriormente, o curso de Bacharelado em Enfermagem forma enfermeiros e não enfermeiros professores, tendo, dessa forma, contribuição limitada ao exercício da docência.

Nas narrativas, evidencia-se Que a formação inicial contribui com a atividade docente no sentido de fornecer a sustentação teórica do conteúdo específico, entretanto não fornece a preparação pedagógica. Desse modo, devido a lacuna na formação pedagógica ter sido relatada como principal obstáculo, os enfermeiros professores afirmam Que a formação continuada é um aspecto crítico e fundamental na superação dos obstáculos.

\section{Proposta de Superação dos Obstáculos Didáticos na Perspectiva dos Pesquisadores}

Respondendo ao objetivo geral da nossa investigação, formulamos uma proposta de superação dos obstáculos didáticos encontrados pelos enfermeiros professores da UESPI através da formação em serviço, priorizando a capacitação pedagógica dos docentes. Vale ressaltar Que era este nosso compromisso desde o início desta pesquisa. Desse modo, nossa preocupação sempre esteve voltada para, além da identificação desses obstáculos, a ajuda aos professores no sentido de superá-los, e assim contribuir para um ensino competente de Enfermagem.

Nossa proposta de superação é a formação continuada numa perspectiva da ação-reflexão-ação. Referimo-nos a uma formação Que considere o docente, suas práticas e suas necessidades, sendo formulada na ação-reflexão-ação construída em um ambiente coletivo e Que vá além de reciclar/treinar/adestrar/capacitar. Por isso, era preciso, inicialmente, conhecermos os obstáculos Que os enfermeiros professores enfrentam para, posteriormente, traçarmos uma proposta de superação com base nos obstáculos vivenciados 
e não em realidades diferentes das vividas pelos sujeitos.

Nesse sentido, entendemos Que a formação continuada é um conjunto de propostas Que objetiva a Qualificação do docente para o exercício competente de sua profissão, incluindo conhecimentos relacionados à sua área de conhecimento, às Questões pedagógicas e às Questões políticas, sociais e culturais.

A nosso ver, os objetivos de um programa de formação continuada para a área devem ser: a) estimular os enfermeiros professores a repensarem sua prática docente e transporem o paradigma tradicional do ensino, tornando-se sujeitos críticos de sua prática e formação; b) instituir novas relações dos professores com os saberes pedagógicos e científicos; c) valorizar os saberes experienciais dos docentes e permitir a troca de experiências e d) fazer da UESPI um espaço coletivo e permanente de reflexão sobre a prática docente, configurando-se uma política de valorização do desenvolvimento pessoal e profissional dos professores.

Com base nos obstáculos identificados pelos sujeitos da pesQuisa elaboramos uma lista de sugestões de temas a serem abordados: o Projeto Político Pedagógico do Curso de Enfermagem da UESPI; a importância da formação continuada para o enfermeiro professor; a Universidade frente à construção de uma prática reflexiva; o desafio da formação pedagógica para o docente enfermeiro; o perfil do docente universitário; a formação do professor reflexivo na Enfermagem; planejamento didático: compromisso sociopolítico do educador; avaliação como instrumento reflexivo da prática pedagógica; integração pesQuisa e docência: condição necessária à prática competente de Enfermagem; metodologia de pesQuisa para o enfermeiro professor; a prática da pesQuisa no ensino superior; a relação professor-aluno no cotidiano universitário; operacionalização dos recursos audiovisuais; uso de multimeios como recursos didáticos; práticas interdisciplinares e o ensino de Enfermagem; o pensamento crítico no processo educativo do curso de Enfermagem e a relevância ética para a prática docente.

\section{CONSIDERAÇÕES FINAIS}

A fundamentação teórica desta pesQuisa revelou-nos Que a preocupação com a formação do enfermeiro crítico, reflexivo e transformador da sociedade é bem recente, sendo que sua efetivação passa obrigatoriamente pela formação dos professores. Para Que haja ensino de Qualidade, é necessário oferecer aos professores uma formação adequada ${ }^{(12)}$. Nesse sentido, a prática pedagógica do enfermeiro professor deve passar por um processo contínuo de reflexão e (re)facção já Que essa postura promove uma prática capaz de modificar o contexto educacional do ensino de Enfermagem, ainda marcado pela transmissão do conteúdo, fragmentação do ensino e dicotomia teoria-prática. Para isso, identificar e superar os obstáculos presentes na ação docente do enfermeiro professor é condição essencial para Que possamos avançar em busca dessa transformação do ensino de Enfermagem.

Assim, evidenciamos alguns pontos conclusivos deste estudo:

- A maioria dos enfermeiros professores do Curso de Enfermagem da UESPI ingressaram na docência em decorrência natural de suas atividades como enfermeiros e, inicialmente, não se Questionaram sobre o ofício de professor;

- Três professores já tinham contato com a profissão docente antes do curso de Enfermagem, o Que, para eles, foi fundamental na sustentação da atuação como professor;

- Todos reconhecem Que o curso de Bacharelado em Enfermagem não fornece a base pedagógica para serem professores e apontam a necessidade de formação pedagógica;

- A docência é uma atividade complexa que requer do enfermeiro professor domínio não somente do conteúdo específico da disciplina Que ministra, mas também conhecimentos pedagógicos;

- A formação pedagógica se dá principalmente em disciplinas de pós-graduação latu sensu e strictu sensu. Do total dos professores investigados, somente três possuem formação pedagógica específica para a docência superior;

- Na construção do processo de tornar-se professor, os enfermeiros apontam a experiência como fator fundamental, seja pela compressão da complexidade do trabalho docente, em Que, cada dia, são evidenciados novos desafios, seja pela (re)construção da prática pedagógica;

- A prática pedagógica dos enfermeiros professores da UESPI não segue uma única teoria pedagógica, sendo pautada em uma mistura de paradigmas Que envolvem a produção do conhecimento, o trabalho conjunto de enfermeiros professores e alunos, o aprender a aprender e ainda características de uma prática tradicional;

- Os enfermeiros professores da UESPI revelam o desejo de uma prática pedagógica Que rompa com o paradigma tradicional e Que coloque o aluno como sujeito do processo de aprender, estando conscientes de que isso se configura como um enorme desafio, mas se mostram dispostos a redirecionar o ensino e a prática de Enfermagem em busca de formar um enfermeiro mais crítico e contextualizado na realidade social;

- O trabalho docente é permeado por vários obstáculos didáticos relacionados ao professor, ao aluno e à instituição.

- Em relação ao professor, os obstáculos apontados foram: deficiência de preparação específica para a docência, trabalho com disciplinas das Quais não se tem vivência, linguagem, prática pedagógica sustentada pela dicotomia teoria-prática e a dificuldade em mudar essa prática;

- Em relação aos alunos, foram apontados como obstáculos didáticos: deficiência na base teórica, ingresso na universidade cada vez mais cedo - imaturidade - e falta de preparo para lidar com a mudança da prática pedagógica do professor;

- Em relação à instituição, os enfermeiros professores apontaram a deficiência de recursos e de condições físicas, campos de estágio saturados e com estrutura e equipamentos antigos, baixos salários e ausência de uma política de formação continuada. Nesse contexto, torna-se imprescindível Que a UESPI valorize os docentes, oferecendo-lhes condições dignas de trabalho, salários justos e uma política de formação em serviço, já Que a formação inicial traz pouca contribuição para o exercício da docência e a formação continuada amplia a compreensão do processo educativo, oferecendo a base teórica para o enfermeiro tornar-se professor;

- As formas de superação dos obstáculos apontadas pelos interlocutores foram principalmente estudar, refletir sobre sua prática, experiência e formação continuada;

- Apontamos como proposta de superação dos obstáculos um projeto de educação continuada coletiva e permanente na perspectiva da ação-reflexão-ação, abordando temas Que têm por objetivo superar os obstáculos da prática docente vivenciados pelos enfermeiros professores da UESPI. 


\section{REFERÊNCIAS}

1. Masetto $M$, organizador. Docência na universidade. Campinas(SP): Papirus; 2001.

2. Bachelard B. A formação do espírito científico: contribuição para uma psicanálise do conhecimento. Rio de Janeiro (RI): Contraponto; 1996.

3. Ministério da Saúde (BR). Conselho Nacional de Saúde. Resolução no 196/96. Diretrizes e normas regulamentadoras da pesquisa envolvendo seres humanos. Inf Epidemiol SUS 1996; 5(2): 17-41.

4. Bardin L. Análise de Conteúdo. Lisboa (POR): Edições 70; 1994.

5. Pimenta SM, Anastasiou LGC. Docência no ensino superior. São Paulo (SP): Cortez; 2005.

6. Rosemberg DS. O processo de formação continuada de professores: do instituído ao instituinte. Niterói (RJ): Walk; 2002.

7. Vasconcellos MLMC. A formação do professor do $3^{\circ}$ grau.
São Paulo (SP): Pioneira; 1996.

8. Batista NA. Desenvolvimento docente na área da saúde: uma análise. Trabalho Educ Saúde 2005; 3(2): 283-94.

9. Rozendo CA. Uma análise das práticas docentes de professores universitários da área de saúde. Rev Latino-am Enfermagem, 1999; 7(2): 15-23.

10. Madeira MZA. A prática pedagógica das professoras do curso de enfermagem: revisitando a construção dos saberes docentes [dissertação]. Teresina (PI): Programa de Pós-Graduação em Educação, Universidade Federal do Piauí; 2006.

1 I. Nacarato AM, Varani A, Carvalho V. O cotidiano do trabalho docente: palco, bastidores e trabalho invisível... abrindo as cortinas. In. Geraldi MG, Fiorentini D, Pereira EMA. Cartografias do trabalho docente. Campinas (SP): Mercado de letras; 2001 . p. 73-104.

12. Nóvoa A. Os professores e sua formação. Lisboa (POR): Dom Quixote; 1995. 